\title{
Excessive Moderator Band in a Female Cat's Left Ventricle
}

\author{
Eduarda Aléxia Nunes Louzada Dias Cavalcanti ${ }^{*}$, Stefânia dos Santos Gazzinelli², \\ Mary Suzan Varaschin ${ }^{3}$, Guilherme Albuquerque de Oliveira Cavalcanti ${ }^{1}$
}

\author{
${ }^{1}$ Department of Veterinary Medicine, Universidade Federal de Pelotas, Pelotas, Brazil \\ ${ }^{2}$ Faculdade de Estudos Administrativos de Minas Gerais (FEAD), Belo Horizonte, Brazil \\ ${ }^{3}$ Department of Veterinary Medicine, Universidade Federal de Lavras, Lavras, Brazil \\ Email:*nuneslouzadadias@gmail.com, stefaniagazzineli@yahoo.com.br,msvaraschin@dmv.ufla.br, guilherme@ufpel.edu.br
}

How to cite this paper: Cavalcanti, E.A.N.L.D., dos Santos Gazzinelli, S., Varaschin, M.S. and de Oliveira Cavalcanti, G.A. (2018) Excessive Moderator Band in a Female Cat's Left Ventricle. Open Journal of Veterinary Medicine, 8, 47-53. https://doi.org/10.4236/ojvm.2018.84006

Received: February 2, 2018

Accepted: April 27, 2018

Published: April 30, 2018

Copyright $\odot 2018$ by authors and Scientific Research Publishing Inc. This work is licensed under the Creative Commons Attribution International License (CC BY 4.0).

http://creativecommons.org/licenses/by/4.0/

\begin{abstract}
This report describes a case of cardiomyopathy associated with excessive moderator bands in a 7 years old cat. In the cat echocardiography examination was observed cardiomegaly, decreased systolic function and thinning of the left ventricle wall. The electrocardiogram showed the occurrence of supraventricular tachycardia. The treatment was initiated with digoxin, furosemide and taurine supplementation, with an improvement of the clinical signs, however the animal died in a fall. The diagnosis of cardiomyopathy associated with excessive moderator band, was based on the multiple cardiac bunds which connect the septum to the free wall of the left ventricle observed in the cat necropsy.
\end{abstract}

\section{Keywords}

Cardiomyopathy, Feline, Cardiac Muscle Bundles

\section{Introduction}

The excessive moderator bands in the left ventricle (MBLV) are a rare congenital anomaly in domestic cats, whose clinical signs are similar to those of most heart diseases [1] [2].

Moderator bands are defined as tendon muscle bundles which connect the septum to the free wall ventricle [3] and in mammals are often found in the right ventricle, and are rarer in the left ventricle [1] [3]. It's believed that the function of these structures is to prevent a great strain during ventricular diastole [2].

While moderator bands aren't related to heart disease in most species, when presented in excess in the left ventricle in cats, they are associated with heart 
disease, due to the decrease of diastolic capacity and the occurrence of electrical conduction disorders [4]. The disease is related to the age of the animal, young animals (mean age of 4 years) tend to develop hypertrophic cardiomyopathy (HCM), while older animals (mean age of 8.7 years) tend to have dilated cardiomyopathy (DCM) secondary to MBLV and has a variable prognosis depending on the quality of the constriction [5].

The objective of this report is to present and discuss the clinical, hematological, radiological, echocardiography, electrocardiographic aspect, the specific treatment and the necropsy findings in a cat that developed congestive heart failure (CHF) due to MBLV.

\section{Case Report}

A female mongrel cat (7 years-old, $3.3 \mathrm{~kg}$ ), was treated at a veterinary hospital located in Belo Horizonte/MG. According to the owner, the animal has had difficulty breathing and decreased appetite for about 30 days, and has been treated for 7 days with enrofloxacin $(2.5 \mathrm{mg} / \mathrm{kg}$ twice daily), furosemide $(2 \mathrm{mg} / \mathrm{kg}$ twice daily) and prednisolone ( $1 \mathrm{mg} / \mathrm{kg}$ twice daily), with the symptoms worsening in the days prior to the visit.

On a physical examination, the patient had severe dyspnea, with wheezing and abdominal breathing pattern, and chest expansion restriction. The auscultation revealed muffled sounds in the broncho-alveolar ventral thoracic region, and crackles in the lung's fields of the dorsal region. The chest percussion sound has showed massive in its ventral portion. At thoracentesis, a $200 \mathrm{~mL}$ of serosanguinous fluid were obtained, and there was improvement in breathing pattern. Hypothermia, tachycardia and dehydration were also observed. Hydration, oxygen and antibiotics therapy was initiated.

The Radiography performed a few hours after the initial treatment already indicated new accumulation of fluid in the chest (Figure 1). However, radiographic studies performed shortly after the second thoracentesis, in which 250 $\mathrm{mL}$ of fluid was obtained, demonstrated the occurrence of cardiomegaly, with a large increase of 11 VHS (VHS reference value $7.5 \pm 0.3$ ) [6].

On the third day of the hospital internment, we opted for the insertion of a chest tube with the purpose of draining the effusion, because daily thoracenteses was necessarily, in which an average of $250 \mathrm{~mL}$ fluid was obtained.

The CBC did not change, but the biochemical changes were found in AST (59 $\mathrm{U} / \mathrm{L}$, reference value $23-43 \mathrm{U} / \mathrm{L})$, the total bilirubin $(2.48 \mathrm{mg} / \mathrm{dL}$, reference value from 0.15 to $0.5 \mathrm{mg} / \mathrm{dL}$ ), phosphorus $(8.4 \mathrm{mg} / \mathrm{dL}$, reference value of 0.5 to $8.14 \mu \mathrm{g} / \mathrm{dL})$ and urea $(112 \mathrm{mg} / \mathrm{dL}$, benchmark $40-60 \mathrm{mg} / \mathrm{dL})$. The pleural fluid, classified as exudates, showed 1027 densities (reference value: $>1015$ ), $3.5 \mathrm{mg} / \mathrm{dL}$ protein (reference value: $\leq 3 \mathrm{~g} / \mathrm{dL}$ ), and its albumin/globulin ratio of 0.9 (reference value: $<0.5$ ). The concentration of nucleated cells was 6800 (reference value: $>1000$ cells), with a predominance of small lymphocytes and intact neutrophils. 


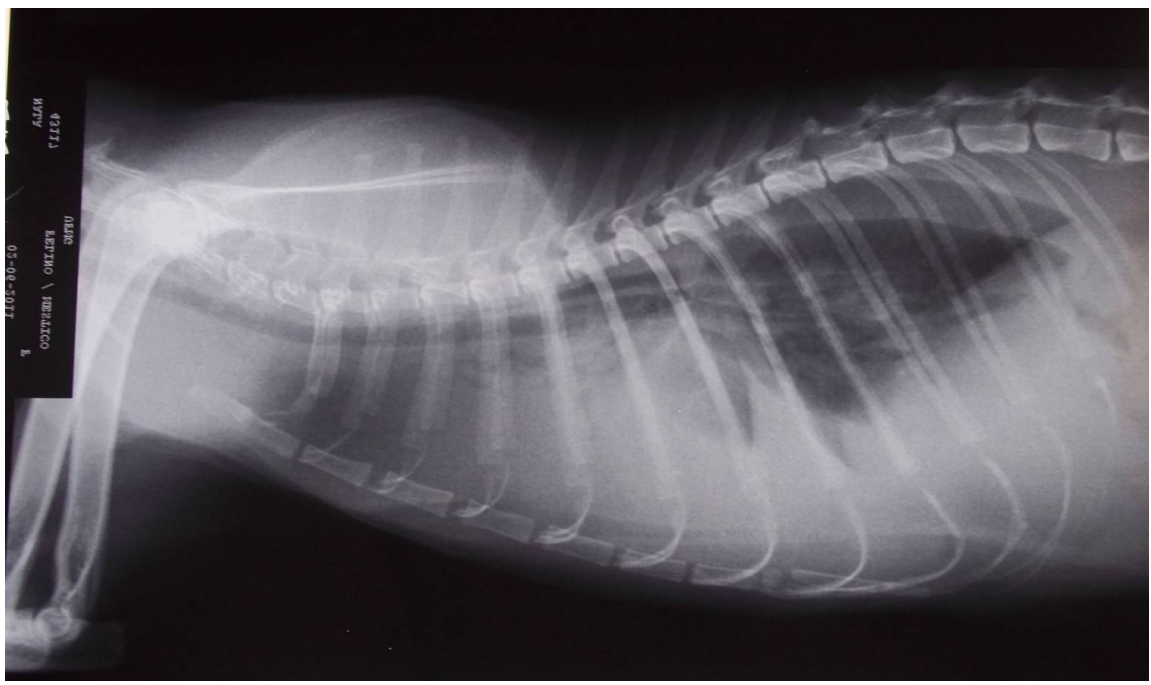

Figure 1. Increased of thoracic ventral radiopacity in lateral-lateral radiographic view, a typical finding of pleural effusion.

Echocardiography examination performed on the fifth day of hospitalization showed large bi-ventricular increase (Left ventricular internal diameter in diastole-19 mm; reference $9 \mathrm{~mm}$ ), left atrial enlargement (Ae/AoB-3.2), right atrial subjectively enlargement (Figure 2), decreased systolic function (EF 27\% $\mathrm{AD} \%$ and $11 \%$ ) and thinning of the left ventricle wall (LV free wall in diastole $=3$ $\mathrm{mm}$ ) [7]. The electrocardiogram showed the occurrence of supraventricular tachycardia.

After the echocardiogram, the treatment was initiated with digoxin $(0.005$ $\mathrm{mg} / \mathrm{kg}$ twice daily), furosemide $(4.0 \mathrm{mg} / \mathrm{kg}$ twice daily) and taurine supplementation (250 mg twice daily), with an improvement of the clinical picture, with progressive reduction in pleural effusion, reaching $8 \mathrm{ml}$ in four days. The electrocardiogram was normalized and the animal received hospital discharge four days after the initiation of the treatment mentioned above.

In a return 10 days after hospital discharge, the owner reported mild tachypnea and $220 \mathrm{~mL}$ of liquid were obtained at thoracentesis. However, the patient was stable for three months, when she fell from the fourth floor of the building where she lived and became deceased. The autopsy showed abdominal effusion, and thoracic and cardiac dilation and a discrete steeper widespread quantity in LV. It was observed that the endocardium still presented itself diffusely thickened and whitened and the presence of moderator bands in both loads between the septum and the ventricular papillary muscle and between the walls of LV (Figure 3).

Microscopy pointed out endocardium with marked proliferation of collagen fibers and fibrous connective tissue, which deepened in some points all the way to the myocardium. The main histopathological findings were moderator bands with the same histological appearance and interspersed with rare myocytes to the same, large nuclei and vesicular or hyperchromatic nuclei and reduced in 


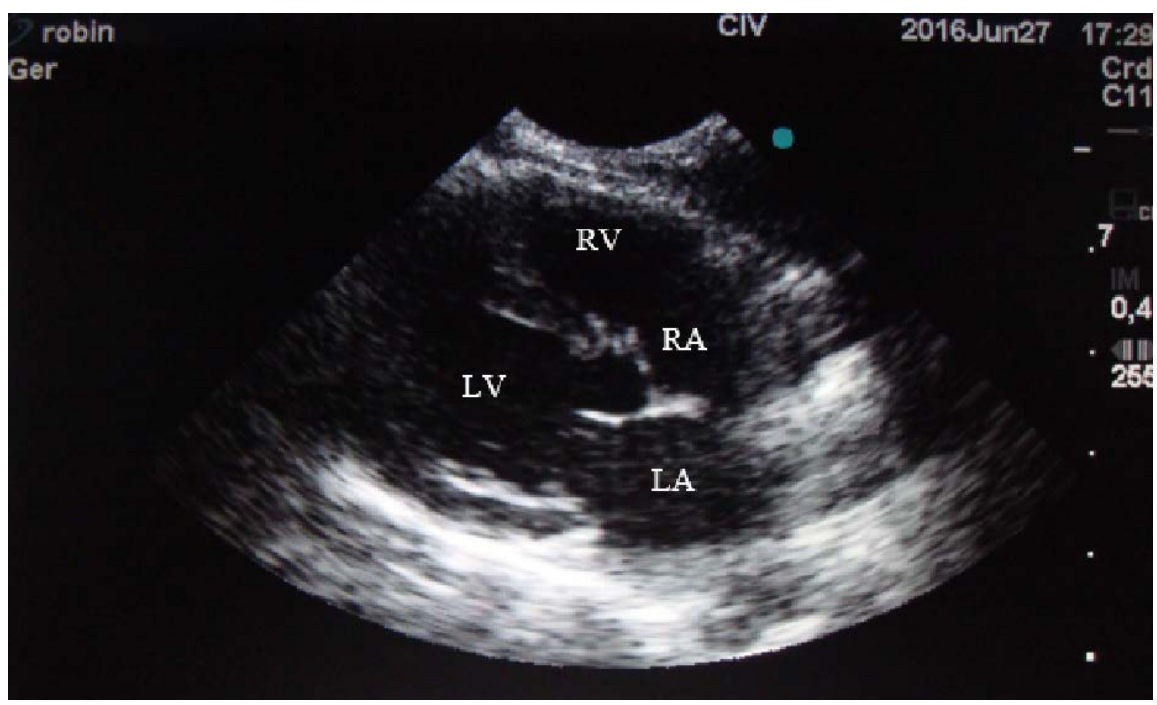

Figure 2. Cardiac enlargement evidenced in the right parasternal view of the echocardiogram. LA-left atrium; RA-right atrium; LV-left ventricle; RV-right ventricle.

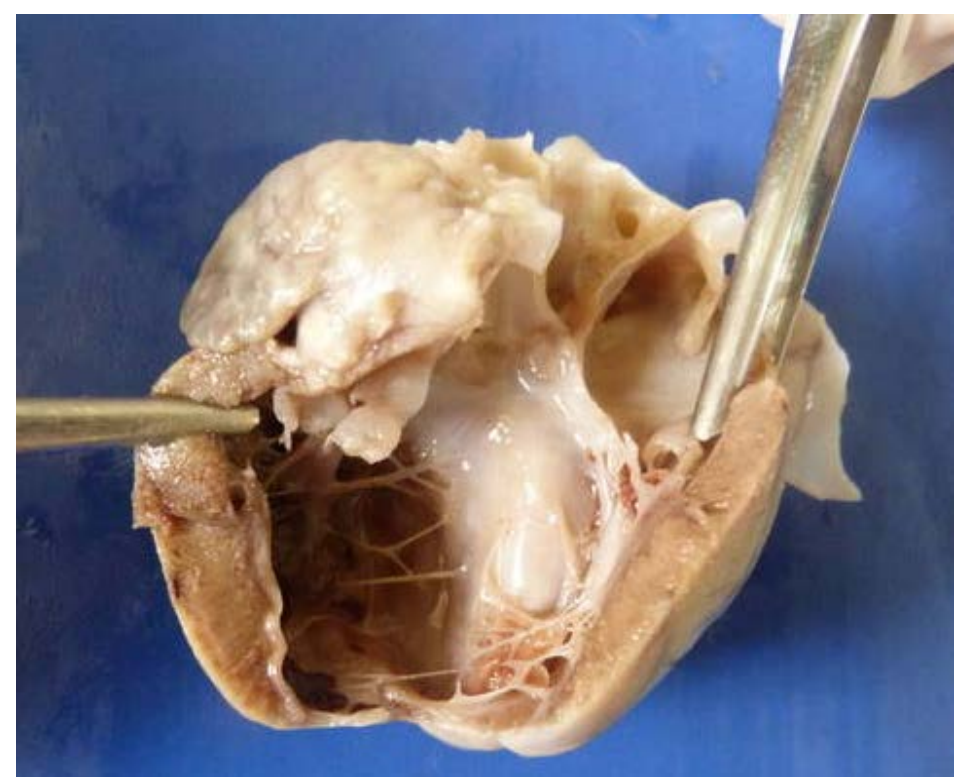

Figure 3. The image shows the endocardium presenting diffusely thickened and white and the presence of moderator bands in both loads between the septum and the ventricular Papillary muscle and between the walls of left ventricle.

volume, and there was a rare focus of lymphocytic infiltration (Figure 4).

\section{Discussion}

The moderator bands are defined as beams that connect the septum to the free wall ventricle, being composed of cardiac muscle fibers, purkinge cells, conjunctive tissues and the endocardium [3] [5]. They are reported as normal structures in the right ventricle of most mammals and are considered rare in left ventricular chamber [1] [3]. It is known that depending on the amount and thickness, 

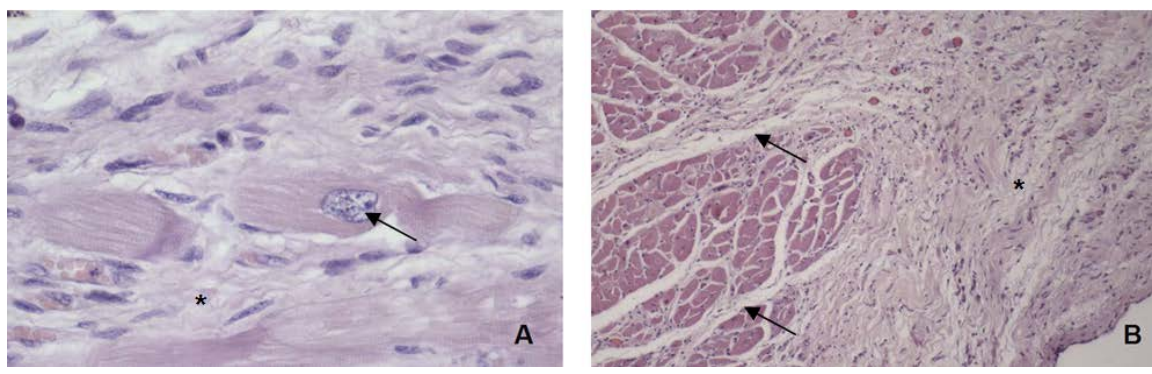

Figure 4. Histopathology slides stained with hematoxylin and eosin shows fibrosis $\left(^{*}\right)$ and increased myocyte nucleus (arrow) in (A) (×200), and the endocardium with marked proliferation of collagen fibers $\left(^{*}\right)$ and fibrous connective tissue (arrow) in (B) $(\times 40)$.

they can cause congestive heart failure (CHF), diastolic deficiency or arrhythmia [8] [9].

The excessive moderator bands in the cat's left ventricle (MBLV) represent a congenital anomaly, and if there isn't a confirmed racial predisposition, cats of any age can be affected [10].

The left ventricular cardiomegaly is the most common abnormality (58\%) among patients with MBLV and it's also more common in older animals suffering from this condition [5]. In this report we observed LV dilation with tapering chamber, matching the most common form of the disease's symptom, besides being the one that occurs the most in older animals carrying these diseases.

It is believed, based on the observed etiology, pathogenesis and histopathology, that a diastolic disability has occurred in this case, with compensatory concentric hypertrophy due to the low cardiac output, leading to the death of the cardiomyocytes and replacement by fibrous tissue with subsequent cardiac dilation, thinning of ventricular wall and a decrease in systolic function observed in echocardiography, as already alerted [2] [11] [12]. However, some authors [1] [13] don't believe in the possibility of MBLV causing heart disease in cats.

There are no significant differences in humans in the prevalence of moderating bands among normal hearts and those with congenital abnormalities [8], and there have also been similar findings in dogs [4]. In felines, however, $90 \%$ of animals that has MBLV have heart disease [5], which leads us to believe that in this species the excessive MBLV constitute a cause of heart disease.

In the study [5] conducted from 1804 autopsies has showed up 21 cats with MBLV, which is consistent with $0.01 \%$ of all domestic cats. Histological findings in hearts with MBLV varied according with the present developed cardiomyopathy. In an animal that develops HCM, there is hypertrophy of muscle fibers, especially of the LV, but in the animals that developed CMD, the cardiac fibers become thinner and are surrounded by a edematous substance or fibrous tissue diffusely [5], furthermore, mononuclear cell infiltration can occur with areas of necrosis, consistent with signs of acute infarction, thromboembolism and fibrosis, and it has not been detected the presence of bacteria in the microscopic analysis [2]. In the present report, there was also a rare focus of infiltrate mononuclear that have probably occurred secondarily to the deaths of cardiomyo- 
cytes. Some authors [2] [5] concluded that the presence of moderator bands, excessive or wide, in LV, can restrict movement and cause cardiopathy.

Domestic felines which have been affected by MBLV, have showed clinical signs similar to those of other heart diseases, lethargy and dyspnea being the most common, and hypothermia and dehydration are also frequent found; it can also occur anorexia, hydrothorax and cardiac murmur. Rarer signs include vomiting, paraplegia due to thrombi, syncope and gallop rhythm [2] [5]. The cat in this report showed the age and the most common clinical signs described in the literature: dyspnea, hypothermia, dehydration, anorexia and pleural effusion.

The ECG changes occur due to cardiac dilatation or the ability of MBLV in conducting erratic electrical stimuli and include right bundle branch block, atrioventricular block, left anterior fascicular, sinus bradycardia [5] and supraventricular tachycardia [14]. In this report supraventricular tachycardia was attributed to severe atrial dilation, which was resolved with the use of dioxin.

It is reported in the scientific community that the levels of ALT, AST, ALP, bilirubin serum, phosphorus and nitrogen may increase due to the hepatic congestion or due to a reduction in renal blood flow which occurs at ICC [15]. Hypokalemia may also occur in anorexic animals [1], so changes in the biochemical evaluation found in this animal are compatible with the CHF.

In cases of MBLV the therapy is applied according to the developed cardiomyopathy. When dilated cardiomyopathy occurs, the indicated treatment is based on the use of digitalis, diuretics, and vasodilators [16], while cases of hypertrophic cardiomyopathy are treated with beta blockers such as atenolol, calcium channel blockers and diuretics [10].

\section{Conclusions}

The animal presented in this report was treated with dioxin and furosemide, with an appropriate framework control during the three follow-up months. The administration of taurine was instituted due to the evidence of dilated cardiomyopathy, which in cats could be related to the deficiency of the amino acid taurine, but the authors believe that the supply of the amino acid did not influence the clinical outcome.

We have concluded, therefore, that treatment with digoxin and furosemide in cats with MBLV CMD may be effective in the short term, however the scientific community needs further studies to evaluate whether the MBLV is actually causing heart disease in domestic cats.

\section{References}

[1] Fox, P.R. (1999) Textbook of Canine and Feline Cardiology, Principle and Clinical Practice. WB Saunders, Philadelphia, 621-678.

[2] Wray, J.D., Gajanayake, J. and Smith, S.H. (2007) Congestive Heart Failure Associated with a Large Transverse Left Ventricular Moderator Band in Cats. Journal Feline Medicine Surgery, 9, 56-60. https://doi.org/10.1016/j.jfms.2006.03.006

[3] Parto, P., Tadjalli, M. and Ghazi, S.R. (2010) Macroscopic and Microscopic Studies 
on Moderator Bands in the Heart of Ostrich (Stuthio camelus). Global Veterinária, 4, 374-379.

[4] Koie, H., Hara, A., Sakai, M., Takiyama, N. and Uechi, M. (2007) Clinical Evaluation of Left Ventricular Moderator Band in 12 Dogs. Journal Veterinary Medicine Science, 69, 965-967. https://doi.org/10.1292/jvms.69.965

[5] Liu, S., Fox, P.R. and Tilley, L.P. (1982) Excessive Moderator Bands in the Left Ventricle of 21 Cats. JAVMA, 180, 1215-1219.

[6] Litster, A.L. and Buchanan, J.W. (2000) Vertebral Scale System to Measure Heart Size in Radiographs of Cats. Journal of the American Veterinary Medical Association, 216, 210-214. https://doi.org/10.2460/javma.2000.216.210

[7] Boon, J.A. (1998) Manual of Veterinary Echocardiography. Willians \& Wilknis, Baltmore, 478 .

[8] Gerlis, L.M., Wright, H.M., Wilson, N., Erzengin, F. and Dickison, D.F. (1984) Left Ventricular Bands: A Normal Anatomical Features. British Heart Journal, 52, 641-647. https://doi.org/10.1136/hrt.52.6.641

[9] Schober, K. and Todd, A. (2010) Echocardiographic Assessment of Left Ventricular Geometry and the Mitral Valve Apparatus in Cats with Hypertrophic Cardiomyopathy. Journal Veterinary Cardiology, 12, 1-16.

https://doi.org/10.1016/j.jvc.2009.09.004

[10] Ferasin, L. (2009) Feline Myocardial Disease 2: Diagnosis, Prognosis and Clinical Management. Journal Feline Medice Surgery, 11, 183-194.

https://doi.org/10.1016/j.jfms.2009.01.002

[11] Baty, C.J., Malarkey, D.E., Atkins, C.E., Defrancesco, T.C., Sidley, J. and Keene, B.W. (2001) Natural History of Hypertrophic Cardiomyopathy and Aortic Thromboembolism in a Family of Domestic Shorthair Cats. Journal Veterinary Internal Medicine, 15, 595-599. https://doi.org/10.1111/j.1939-1676.2001.tb01598.x

[12] Wolf, O.A., Imgrund, M. and Wess, G. (2017) Echocardiographic Assessment of Feline False Tendons and Their Relationship with Focal Thickening of the Left Ventricle. Journal of Veterinary Cardiology, 19, 14-23.

https://doi.org/10.1016/j.jvc.2016.08.008

[13] Kimura, Y., Karakama, S., Kobayashi, M. and Machida, N. (2015) Incidence, Distribution and Morphology of Left Ventricular False Tendons in a Cat's Hearts. Journal of Veterinary Medicine, 45, 490-493..

[14] Ferasin, L., Sturgess, C.P., Cannon, M.J., Caney, S.M., Gruffydd-Jones, T.J. and Wotton, P.R. (2003) Feline Idiopathic Cardiomyopathy: A Retrospective Study of 106 Cats (1994-2001). Journal Feline Medicine Surgery, 5, 151-159. https://doi.org/10.1016/S1098-612X(02)00133-X

[15] Cavalcanti, G.A.O., Tatibana, L.S., Varaschin, M.S., Araújo, R.B. and Costa Val, A.P. (2011) Atrial Septal Defect in an Elderly Dog. Arquivo Brasileiro Medicina Veterinaria e Zootecnia, 63, 503-507. https://doi.org/10.1590/S0102-09352011000200033

[16] Pion, P.D., Kittleson, M.D., Thomas, W.P., Delellis, L.A. and Rogers, Q.R. (1992) Response of Cats with Dilated Cardiomyopathy to Taurine Supplementation. Journal of the American Veterinary Medical Association, 201, 275-284. 